\title{
Infantile handling and performance in the T-maze'
}

RODERICK WONG

UNIVERSITY OF BRITISH COLUMBIA

One group of rats was given tactile stimulation on Days 3-21 of life, and a control group was not disturbed. At 60 days, $S$ s were given acquisition trials in a T-maze for a 10 day period. At Day 70 Ss were given 10 extinction trials per day over 8 days. Comparisons betweer the handled and the nonhandled groups showed no differences in running time nor in choice behavior during both acquisition and extinction.

Although evidence on the facilatory effects of infantile stimulation of rats on their subsequent performance in avoidance learning is substantial and relatively consistent, data on the effects of this variable on an animal's performance in an appetitive learning situation remain sparse and equivocal (Berstein, 1957; Spence \& Maher, 1962). In the earlier Berstein (1957) study, a comparison was made between the choice behavior of handled and nonhandled rats. The animals were reinforced by a food pellet for choosing the illuminated side of a $\mathrm{T}$-shaped discrimination box. Results showed that the handled animals made fewer errors during both acquisition and extinction trials than did the nonhandled control animals. It should be noted that the handling occurred during the postweaning period.

A more recent study by Spence \& Maher (1962) compared the performance of handled and nonhandled rats in a runway where food served as their reinforcer and running time as the response measure. Differences between the handled and the nonhandled groups were not significant. However, further analysis revealed that Ss which were handled before weaning showed faster running times than those which received this treatment after weaning. The performance of the untreated Ss occupied a position intermediate to those in the preweaning and postweaning conditions.

An obvious factor which accounts for the conflicting results obtained in the previous studies is that different responses were used. It is possible that a simple response measure such as a running speed is not facilitated by the infantile handling variable whereas performance on a more complex task such as light-dark discrimination is facilitated by this variable. As a means of testing this explanation of the results of the studies just cited, the present experiment was designed to compare early handled rats with nonhandled ones on a task in which joint measures were taken of their running speed and choice behavior.

\section{Method}

The Ss were 24 female albino rats of the Wistar strain. They were randomly assigned from their litters after birth to either the handled or the control condition, and were housed by litters until they were weaned at 21 days. On the third day after birth Ss from the handled condition were removed from the cage and were handled by having their tails stroked vigorousiy with the felt brush of a marking pen. The ink from the brush left a mark on S's tail which allowed E to identify the handled from the nonhandled Ss within a given litter. This procedure was sufficient to cause all Ss to squeal during the handling period, and this was continued once a day through Day 21. On Day 22 all Ss were weaned and were housed, six in a cage, in 10 in. $x 12$ in. $x 7-1 / 2$ in. cages. The handled and nonhandled Ss were grouped in separate cages and were housed there until the age of 60 days. They then were moved into individual $7 \mathrm{in}$. $\mathrm{x} 9-1 / 2$ in. $\mathrm{x} 7 \mathrm{in}$. cages and were placed on a diet of $10 \mathrm{gm}$ of food ration per day. The Ss were habituated to this maintenance schedule for eight days and then were given two days of pretraining in the T-maze. They were provided with equal experience in the rewarded and nonrewarded goal-boxes by a sequence of free and forced trials. Four trials were given during each of the two days.

The T-maze consisted of a start-box, alley, and two goal-boxes all 3 in. wide and 6 in. high. The start-box and the goal-boxes were $12 \mathrm{in}$. in length. The stem of the maze was $24 \mathrm{in}$. long, and each arm was 4 in. long. The entire apparatus, with the exception of the white and black goal-boxes, was painted gray. The goal-boxes were interchangeable, and gray sliding doors were placed at the entrance to each as well as at the exit of the startbox. Two photoelectric cells were placed in the stem, 2 in. and $23-1 / 2$ in. from the start-box, respectively, and the running time was measured by a Lafayette timer.

After Ss received pretraining they were given 5 free trials for the next four days and 10 runs a day for eight thereafter. Half of the Ss were reinforced with a 0.45 gm pellet of wet mash for choosing the white goal-box, and the other half were reinforced for choosing the black goal-box. The location of the positive side was randomly varied, and the noncorrection method was used.

Following the 100 acquisition trials, each $\mathrm{S}$ received 10 extinction trials per day over eight days. Running time and choice behavior measures were taken during acquisition and extinction.

\section{Results and Discussion}

A comparison between the running time scores of the handled and the nonhandled animals during acquisition revealed no difference $(F=0.90, p>.05)$. This result replicates Spence \& Maher's (1962) runway data. However, Berstein's (1957) results on the facilitatory effects of early handling on choice behavior were not replicated. The analysis of the error scores of the two groups yielded an $F$ of $1.11(p>.05)$. Such results support 
Spence \& Maher's contention that early nonspecific sensory-perceptual stimulation does not have a beneficial effect of learning ability per se, and that differences in performance between stimulated and nonstimulated animals may be attributable to differences in the degree to which interfering emotional responses are elicited.

The extinction data also failed to indicate a difference between the groups. The resulting $F$ for the running time scores was $1.96(p>.05)$, and the comparison between the error scores of the groups yielded an $F$ of $1.01\left(p>{ }_{0} 05\right)$. Data on the number of trials in which $S$ failed to run within a $120 \mathrm{sec}$. period also revealed no difference between the groups $(F=1.31, p>.05)$. In general these results indicate that Berstein's notion that the relationship between the experimenter and the experimental animal "acts as a secondary reinforcement in a learning situation, above and beyond its anxiety-reducing function" is a proposition which remains to be demonstrated.

\section{References}

Berstein, L. The effects of variations in handling upon learning and retention. J. comp. physiol. Psychol., 1957, 50, 162-167.

Spence, J. T., \& Maher, B. A. Handling and noxious stimulation of the albino rat: II. Effects on subsequent performance in a learning situation. J. comp. physiol. Psychol., 1962, 55, 252-255.

\section{Note}

1. This research was supported by a grant from the Dean's Committee on Research of the University of British Columbia. 